\title{
Abundance estimates of the Indo-Pacific lionfish Pterois volitans/miles complex in the Western North Atlantic
}

\author{
Paula E. Whitfield · Jonathan A. Hare - Andrew W. David - Stacey L. Harter • \\ Roldan C. Muñoz $\cdot$ Christine M. Addison
}

Published online: 6 February 2007

C) Springer Science+Business Media B.V. 2007

\section{Erratum to: Biol Invasions DOI 10.1007/s10530-006-9005-9}

We used raw catch-per-unit-effort data as a measure of relative grouper abundance in Fig. 3c. Owing to the vagaries of fishery dependent landings data, this use of CPUE data is inappropriate, and all references to Fig. $3 \mathrm{c}$ as verification of rank grouper abundance should be ignored. Figure $3 \mathrm{c}$ should also not be used to derive a lionfish stock estimate as lionfish are not currently found in high numbers in the head boat fishery.

All comparisons between grouper abundance and lionfish abundance are from density estimates found in the survey areas only. The site locations

The online version of the original article can be found at http://dx.doi.org/10.1007/s10530-006-9005-9.

P. E. Whitfield $(\bowtie) \cdot$ J. A. Hare · R. C. Muñoz ·

C. M. Addison

NOAA Beaufort Laboratory, 101 Pivers Island Road, Beaufort, NC 28516, USA

e-mail: paula.whitfield@noaa.gov

Present Address:

J. A. Hare

NOAA NMFS NEFSC, Narragansett Laboratory, 28

Tarzwell Drive, Narragansett, RI 02882, USA

\section{A. W. David · S. L. Harter}

NOAA NMFS SEFSC, Panama City Laboratory, 3500 Delwood Beach Road, Panama City, FL 32408, USA were not selected based on a stratified random design. Presently, habitat maps are not available to support such a design. Statements of comparison are not meant to be of total population abundance for either lionfish or groupers.

Behavioral differences between grouper and lionfish may lead to differences in detectability via visual surveys. While there are methods to evaluate these differences, the logistical constraints of diving in deep water precluded their employment in this study. However, published values of detectability were used as a correction factor (Stewart and Beukers 2000) in an attempt to correct for this possible source of error. Visibility was generally very good on the survey sites and experienced divers conducted the transect surveys.

Our acknowledgement of Erik Williams and Mike Burton does not imply their agreement with the content of the manuscript. However we do appreciate their time and effort during the in-house review process.

Correction date received: 12 December 2005 